\title{
Does Combined Heat and Power Play the Role of a Bridge in Energy Transition? Evidence from a Cross-Country Analysis
}

\author{
Hyo-Jin Kim, Jeong-Joon Yu and Seung-Hoon Yoo * \\ Department of Energy Policy, Graduate School of Energy \& Environment, Seoul National University of \\ Science \& Technology, 232 Gongreung-Ro, Nowon-Gu, Seoul 01811, Korea; hjinkim@seoultech.ac.kr (H.-J.K.); \\ jjyuglobal@seoultech.ac.kr (J.-J.Y.) \\ * Correspondence: shyoo@seoultech.ac.kr; Tel.: +82-2-970-6802
}

Received: 31 December 2018; Accepted: 11 February 2019; Published: 16 February 2019

\begin{abstract}
In an era of energy transition involving an increase in renewable energy and a reduction in coal-fired power generation and nuclear power generation, the role of combined heat and power (CHP) as a bridging energy is highly emphasized. This article attempts to look empirically into the impact of increasing the share of renewable energy in total electricity generation on CHP share in total electricity generation in a cross-country context. Data from 35 countries during the period 2009-2015 were used, and the least absolute deviations estimator was applied to obtain a more robust parameter estimate. The results showed that a $1 \% \mathrm{p}$ increase in the share of renewable energy significantly increased the CHP share by $0.87 \%$ p. Therefore, the hypothesis that CHP serves as bridge energy in the process of energy transition was established.
\end{abstract}

Keywords: combined heat and power; bridge energy; renewable energy; cross-country analysis; robust estimator

\section{Introduction}

As of 2017, the electricity consumed in South Korea was generated from coal (45.4\%), nuclear power (30.3\%), natural gas (NG) $(16.9 \%)$, and renewable energy (6.2\%). The ratio of coal and nuclear power to total generation amounted to $75.7 \%$ and is expected to reach $80 \%$ by 2030 unless some measures are taken. However, coal-fired power generation has been creating environmental problems by emitting large amounts of carbon dioxide $\left(\mathrm{CO}_{2}\right)$ and air pollutants, and nuclear power has been causing serious safety concerns since the Fukushima nuclear accident in 2011 [1,2].

Thus, a number of countries around the world are pursuing a policy of reducing coal-fired and nuclear power generation and increasing the use of renewable energy (RE). This policy is often called the energy transition policy [3-5]. For instance, South Korea is pushing for the so-called "Renewable Energy 3020 Plan" to increase the share of RE in total power generation from only $2.2 \%$ in 2016, to $20 \%$ by 2030. Accordingly, the government is pushing for an energy transition to reduce the share of coal and nuclear power and increase the share of RE and NG in order to alleviate the biased mix of power generation sources and promote balanced development among them.

RE has the advantage of not emitting $\mathrm{CO}_{2}$ and air pollutants, whereas it has the disadvantage of intermittency and uncertainty, which are greatly affected by weather conditions, such as relying on the amount of sunshine and wind volume. In other words, if the amount of sunshine is not good, or the wind is not strong, RE is not able to generate electricity, resulting in a power outage. Therefore, it is imperative to expand backup facilities to overcome these shortcomings. Major backup facilities include pumping-up power generation, energy storage systems, and NG-fired power generation. Of these, the expansion of NG-fired power generation is the most effective alternative, as the construction of 
pumping-up power plants can seriously damage the natural environment, and energy storage systems incur a higher cost than other facilities.

In particular, combined heat and power (CHP) generation, which can produce both heat and electricity at the same time, is so efficient that it can reduce energy use and even mitigate $\mathrm{CO}_{2}$ and air pollutant emissions [6-12]. For example, a CHP system using NG emits $48.9 \%$ less $\mathrm{CO}_{2}$ than separate heat and power systems using an NG-fired boiler and a fossil fuel-fired power plant [13]. According to the United States Department of Energy and the United States Environmental Protection Agency [14], the government will reduce emissions by 150 million metric tons of $\mathrm{CO}_{2}$ each year by installing new CHP plants with a total capacity of $40 \mathrm{GW}$ by 2020 .

In sum, $\mathrm{CHP}$ is a powerful means of mitigating $\mathrm{CO}_{2}$ and air pollutant emissions as well as an effective instrument in coping with the intermittency and uncertainty of RE. Consequently, CHP receives much attention on its role as a bridging energy in transitioning from the fossil energy era to the RE era [15]. Therefore, this study investigated whether the share of RE in total electricity generation makes an impact on the CHP share in total electricity generation and, if so, how big this is in order to obtain policy implications for expanding the CHP supply. The results of this article are useful, because there has been little research done on this topic.

Data from 35 countries during the period 2009-2015 were used for a cross-country comparison. For this purpose, a simple equation with the endogenous variable CHP share and the exogenous variables constant and RE share was estimated. In doing so, we used the robust estimation of the least absolute deviations (LAD) estimator rather than the least squares (LS) estimator to avoid its vulnerability to the existence of any possible outliers and to avoid the assumption of the distribution of error terms. The rest of the article has three sections. The next section explains the model and data adopted in the article. The third section presents the estimation results of the model and provides a discussion of the results. The final section concludes the study.

\section{Methods and Materials}

\subsection{Methods}

For simplicity, we applied a simple regression model to uncover the relationship between the share of CHP and the share of RE. The simple regression model was composed of a dependent variable and two independent variables [16]. The dependent variable was the share of CHP, and the independent variables were the constant and the share of RE. Thus, it was assumed that all the effects of other factors on the share of CHP other than the share of RE were included in the constant term. Moreover, characterizing the relationship by a linear form gave us the following econometric specification:

$$
S_{t, \mathrm{CHP}}=\alpha_{0}+\alpha_{1} S_{t, R E}+\varepsilon_{t}
$$

where $t$ denotes $t$ th observation for $t=1, \ldots, T, S_{t, C H P}$ and $S_{t, R E}$ are the share of CHP and the share of RE in total power generation, respectively, $\alpha_{0}$ and $\alpha_{1}$ are parameters to be estimated, and $\varepsilon_{t}$ is a disturbance term.

Although Equation (1) is quite simple, it has the advantage of being able to explicitly look at the relationship between $S_{C H P}$ and $S_{R E}$. It is assumed that all other factors affecting $S_{C H P}$ are included in the constant term. In spite of that, because there may be other factors that affect $S_{C H P}$ but are missing from Equation (1) and the linear specification is not appropriate, a Ramsey's [17] regression equation specification error test (RESET) was applied to check for the existence of any specification errors.

As will be explained below, the hypothesis of no specification error cannot be rejected. In the LS estimation, $\varepsilon$ is assumed to be distributed normally with a mean of 0 and a standard deviation $\sigma$. However, this normality assumption is usually too restrictive to be satisfied. In this case, a semi-parametric alternative that does not assume normality of the disturbance term should be 
employed. For this purpose, this article adopted the LAD estimator: Let the LAD estimator for $\alpha$ be $\alpha_{L A D}$ where $\alpha=\left(\alpha_{0}, \alpha_{1}\right)$. According to Bassett and Koenker [18], $\alpha_{L A D}$ is given by

$$
\alpha_{L A D}=\underset{\alpha_{0}, \alpha_{1}}{\operatorname{argmin}} \sum_{t=1}^{T}\left|S_{t, C H P}-\left(\alpha_{0}+\alpha_{1} S_{t, R E}\right)\right| .
$$

Buchinsky [19] examined six approaches to obtaining the variance matrix for $\alpha_{L A D}$. They are the design matrix bootstrap, error bootstrapping, order statistic, sigma bootstrap, homoscedastic kernel, and heteroscedastic kernel. He showed that the design matrix bootstrap is favored for general cases. Thus, this article employed the design matrix bootstrap method to get the variance matrix with the number of replications being 5000 .

\subsection{Materials}

Three important points need to be considered in the use of data in a cross-country analysis. First, cross-country analysis is used to establish a comparable set of data by country and year. In other words, international and intertemporal comparability of data is a key element of the cross-country analysis. For monetary unit variables, a price index such as the purchasing power parity shall be used to make them comparable by having a constant price. For physical unit variables other than monetary unit variables, intertemporal comparability should be considered. The variables used in this study are the ratios of renewable energy and CHP power in the total power generation of the country concerned. Thus, they are comparable by country as well as by year. Therefore, there is little difficulty in dealing with both variables in a single equation.

Second, sufficiently reliable data must be obtained from a credible agency or source. This is because the reliability of the analysis results cannot be secured if data based on simple estimation or data arbitrarily collected by researchers are used. Regarding the percentage of electricity production from renewable sources, the International Energy Agency (IEA) collects data from countries and builds databases, and the World Bank regularly compiles the data contained in these databases to publish a report on world development indicators every year. Therefore, this study intended to extract the data on the percentage of electricity production from renewable sources from the World Bank [20] and then utilize them. Next, it is important to obtain reliable data on the percentage of CHP in total power generation, which is included neither in the IEA database nor in that of the World Bank [20]. In this regard, Euroheat and Power, which is the international network for grid energy and filters possible heating and cooling in Europe and beyond, publishes a yearbook of district heating and cooling. To the best of their knowledge, EuroHeat and Power's [21-24] reports are the only dataset that contains comparable CHP shares by country, and thus they were utilized in this study. In summary, the data used here did not cover the entire period from 2009-2015 but did cover 2009, 2011, 2013, and 2015. Moreover, there were missing data for some years or countries.

Third, it is best to conduct a cross-country analysis using panel data that have all the countries' and years' observations. Unfortunately, however, the datasets of the World Bank [20] and Euroheat and Power [21-24] do not include observations for some countries and/or some years. Moreover, since Euroheat and Power's reports are published only four times every two years, data on the share of CHP have been available only for four years $(2009,2011,2013$, and 2015). Thus, because of the limitations in acquiring data, unbalanced panel data rather than the balanced panel data was used in this study. In such cases, the dynamic panel model is not applicable, and one of two methods is usually applied in the literature dealing with cross-country analysis. The first method is to take an average value for several years, derive one observation for each country, and then apply a cross-sectional analysis, where the number of observations is 35. A seminal work adopting this approach was Mankiw et al. [25]. The second method is to perform a cross-sectional analysis with pooled data, in which case the number of observations is 84 . For example, $\mathrm{Li}$ and Lin [26] applied this approach to a cross-country analysis 
with 73 countries. This study adopted the latter method in that it utilized more observations than the first approach.

In summary, Euroheat and Power [21-24] provided the data on $S_{C H P}$ and the data on $S_{R E}$, which relate to electricity production from renewable sources excluding hydroelectric energy, data on which were obtained from the World Bank [20]. The data did not cover the entire 2009-2015 period but did cover 2009, 2011, 2013, and 2015. Moreover, there were missing data for some years or countries. The variables used in this article are explained in Table 1.

Table 1. Description of variables in the model.

\begin{tabular}{cccc}
\hline Variables & Definitions & Mean & Standard Deviation \\
\hline$S_{C H P}$ & $\begin{array}{c}\text { Percentage of combined heat and power in } \\
\text { total power generation (of available } \\
\text { observations during 2009-2015) } \\
\text { Percentage of electricity production from } \\
\text { renewable sources excluding hydroelectric } \\
\text { energy in total power generation (of } \\
\text { available observations during 2009-2015) }\end{array}$ & 10.91 & 17.37 \\
\hline
\end{tabular}

Source: Euroheat and Power [21-24] and the World Bank [20].

A list of the sample countries, in alphabetical order, used in this analysis is Austria, Belarus, Bulgaria, China, Croatia, the Czech Republic, Denmark, Estonia, Finland, France, Germany, Greece, Hungary, Iceland, Ireland, Italy, Japan, Kosovo, Latvia, Lithuania, Macedonia, Norway, Poland, Romania, Russia, Serbia, Slovakia, Slovenia, South Korea, Sweden, Switzerland, the Netherlands, the United Arab Emirates, the United Kingdom, and the United States.

\section{Results and Discussion}

\subsection{Estimation Results of the Model}

We can estimate Equation (1) using the LS estimation method. The LS estimation results are given in Table 2. All the coefficient estimates were statistically significant at the $1 \%$ level. For the purpose of implementing a specification test for the model, a Ramsey's [17] RESET test was applied and its test statistic was computed to be 0.055 under the null hypothesis; therefore, the model was correctly specified and did not suffer from omitted variable bias. The null hypothesis could not be rejected at the $1 \%$ level, as its $p$-value was calculated to be 0.814 . Thus, the model used here was very simple, but it did not seem to have a specification error.

Table 2. Estimation results of the model.

\begin{tabular}{ccc}
\hline Variables $^{\text {a }}$ & Least Squares Estimation & Least Absolute Deviations Estimation $^{\mathbf{b}}$ \\
\hline Constant & $10.0965(4.77)^{*}$ & $5.9299(3.27)^{*}$ \\
$S_{R E}$ & $0.9687(6.71)^{*}$ & $0.8670(3.14)^{*}$ \\
$R^{2}$ & 0.3548 & 0.3548 \\
Number of observations & 84 & 84 \\
\hline
\end{tabular}

Notes: The dependent variable is the share of combined heat and power in total power generation. ${ }^{\text {a }}$ The variable is defined in Table 1 . The numbers in parentheses below the coefficient estimates are $t$-values. ${ }^{b}$ The standard errors were computed from 5000 bootstrap replications. * indicates statistical significance at the $1 \%$ level.

A test given in Jarque and Bera [27] can be applied to test whether the assumption of normality in the error term is satisfied or not. The test statistic under the null hypothesis that the disturbance term is distributed as normal is 15.20 . Given that $\chi_{0.01}^{2}(2)=9.21$, the null hypothesis can be rejected at the $1 \%$ level. Thus, as an alternative to the LS estimation, the LAD estimation method was adopted here. As explained above, the LAD estimator does not require any assumptions regarding the distribution 
of the disturbance term. Moreover, it is known to be robust to any possible outliers, whereas the LS estimator can be vulnerable to them. The robustness, $\sqrt{T}$-consistency, and asymptotically normality properties were proved for the LAD estimator [18]. The results from estimating the equation using the LAD estimation are also shown in Table 2.

\subsection{Discussion of the Results}

Although the equation is simple, some interesting findings emerge from Table 2. First, in the results from applying both the LS and LAD estimators, the coefficient estimates for the RE share term were consistently positive. In addition, they were statistically distinguishable at the $1 \%$ level. This indicates that, for the sample countries, a high RE share in a country increased its CHP share significantly. We can conclude that RE leads to more CHP. Therefore, the hypothesis that CHP serves as a bridging energy in the process of energy transition can be established.

No significant difference was found between the LS estimates and LAD estimates. Nevertheless, because the latter is known to be robust to outliers without making the restrictive assumptions required by the former, it appears to be desirable to use the results based on the latter. A 1\%p increase in the RE share resulted in a $0.87 \% \mathrm{p}$ increase in the CHP share. Considering that the increase in RE also increases the intermittent and uncertain power supply, it can be seen that countries pursuing energy transition are adopting $\mathrm{CHP}$ as a practical alternative to overcome these problems. A summary of procedures for conducting this study is shown in Figure 1.
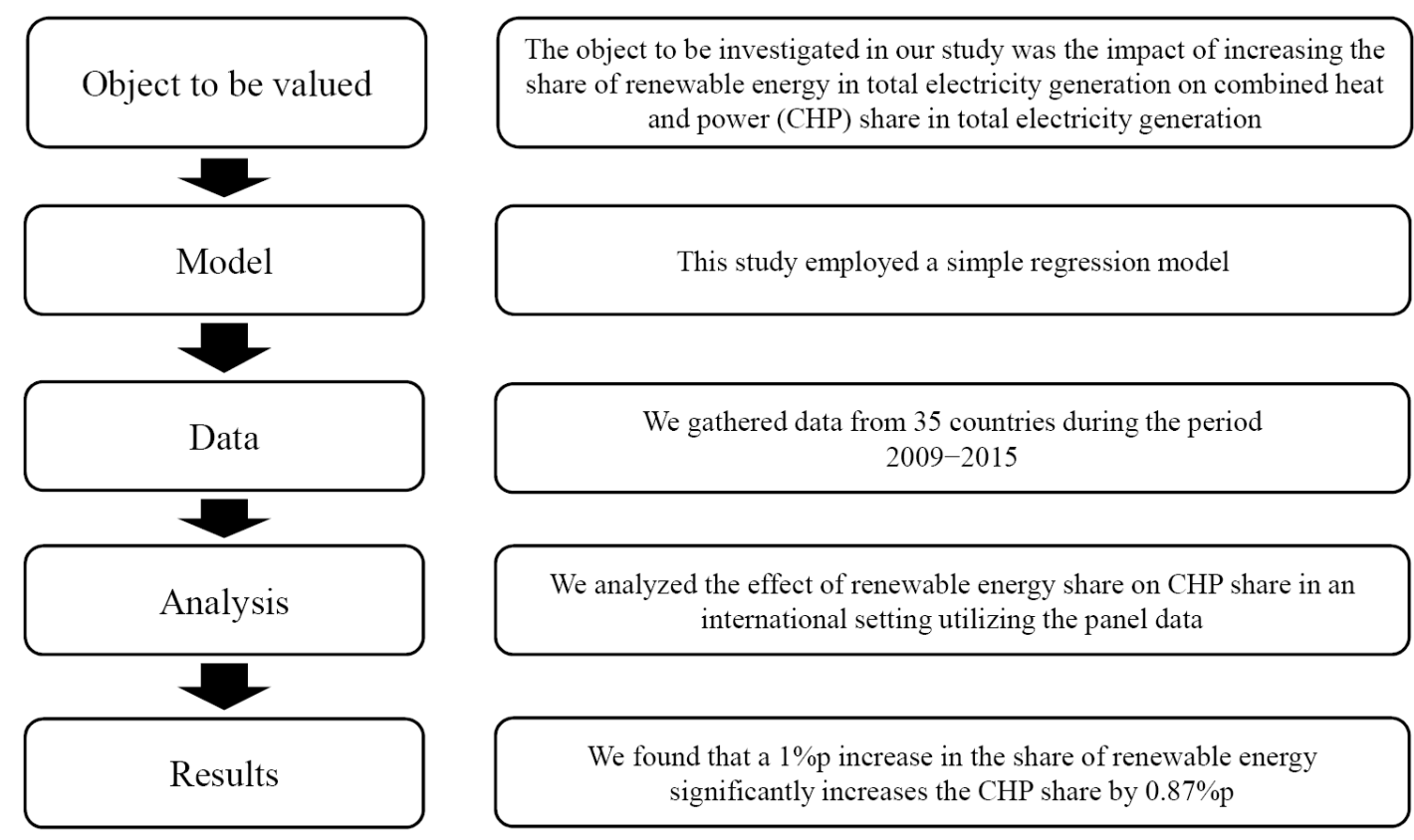

Figure 1. Summary of procedures for conducting this study.

$\mathrm{CHP}$ is able to start right away with a large capacity for power supply. Moreover, although a CHP plant is also essentially a thermal power plant using fossil fuels, it emits less $\mathrm{CO}_{2}$ and air pollutants than other forms of thermal power generation, because it produces both heat and electricity at the same time. Therefore, it is natural for the utilization of CHP to increase when the supply of RE is disrupted. In particular, countries such as South Korea, which have no power supply system connected to foreign countries, should also push for the expansion of CHP along with the expansion of RE. Interestingly, it is clear from the results of this study that CHP is not a substitute for RE but a complement.

There is one more point to note regarding the relationship between RE and CHP. In order to greatly expand RE, large-capacity RE complexes are actively being constructed instead of distributed RE. For example, the development of solar or wind farms with GW-scale capacity is being promoted. Most 
of these farms are away from areas that consume a lot of electricity. In other words, they are limited by a non-distributed power source rather than a distributed power source. Because a non-distributed power source requires the installation of long-distance transmission facilities, regional conflicts may arise that are difficult to resolve over the construction of transmission facilities [28,29]. However, CHP is the only large-capacity generator that can be located in large power-demanding areas, such as large cities and industrial complexes. Therefore, if it is difficult to push for large-scale RE complexes due to civil complaints related to the construction of transmission facilities, pushing ahead with CHP, which can be located in large power-demanding areas, can have a double advantage.

A number of studies on the role of CHP in energy transition can be found in the literature. For example, McKinsey and Company [30] showed that, on the basis of the current price and the performance of various technologies, investing in CHP has an economic advantage over many other environmentally-friendly technologies. Shipley et al. [31] reported that by using CHP today, the United States already avoids more than 1.9 Quadrillion British thermal units (Quads) of fuel consumption and 248 million metric tons of carbon dioxide $\left(\mathrm{CO}_{2}\right)$ emissions annually compared to traditional separate production of electricity and thermal energy. This $\mathrm{CO}_{2}$ reduction is the equivalent of removing more than 45 million cars from the road. Moreover, $\mathrm{CHP}$ is one of the most cost-effective methods of reducing $\mathrm{CO}_{2}$ emissions [7].

Beith [32] claimed that CHP is a bridging technology to a renewable future, but it should be recognized more as a foundation on which the future can be built. Fogarty and Lamb [33] indicated that $\mathrm{CHP}$ power plants are located at the site of the industrial steam or process of heat users or at a district heating/cooling system and provide the ability to work with one fuel twice, and CHP projects provide a bridge to reduce $\mathrm{CO}_{2}$ emissions. Shao et al. [34] argued that with the increasing penetration of RE generation, CHP plants have a responsibility to provide flexible services in accommodating RE generation. In particular, CHP is expected to play the role of bridging energy as a practical means of coping with the intermittent and uncertain nature of RE generation in an era of increasing renewable energy. This is because CHP not only enables an immediate response to changes in demand for electricity, but it also has the public acceptability to be located within demand areas such as urban areas [29]. Therefore, CHP can contribute to enhancing the sustainability of electricity supply.

As far as the authors are aware, unfortunately, there have been no studies dealing with the role of CHP in a cross-country setting similar to the structure covered by this study. Thus, it is impossible to directly compare the results of this study with the results of previous studies. In spite of that, former work that studied the role of CHP as bridging energy in energy transition emphasized CHP as a cost-effective means of reducing $\mathrm{CO}_{2}$ emissions or qualitatively analyzed the role of $\mathrm{CHP}$ in securing the stability of power supply, even in the event of expanding RE. However, this paper empirically confirmed from the cross-country analysis that the expansion of RE leads to the expansion of CHP. This is an interesting feature of this paper.

\section{Conclusions}

The main concern of this article was whether the influence of RE share on CHP share is significant or not and, if it is, what its magnitude is. To deal with this issue, internationally comparable data for 35 countries during the period 2009-2015 were employed. Moreover, a robust estimator of LAD was applied. The model used was simple but fitted the data well. As far as the authors know, this is the first study to investigate the effect of RE share on CHP share in an international setting through a cross-country analysis.

The results indicate that the level of RE share of a country positively and significantly affected the CHP share for the sample countries. It can be concluded that a high RE share of a country increases its CHP share. This implies that CHP can play its role as a bridgng energy in transitioning from the fossil energy era to the RE era. The suggestion that countries attempting to increase RE also need to make an effort to raise CHP share seems to be supported by the available data. More specifically, a $1 \%$ p increase in the RE share yields a $0.87 \%$ p increase in the CHP share. 
In some respects, the framework of this study needs to be expanded in future studies. First, new implications or insights may be gained if a wider range of quality panel data are obtained and examined. As mentioned earlier, this study used data from 35 countries over four years, but only 84 observations were actually available. Consequently, this study failed to perform a panel analysis or dynamic panel analysis due to limitations of data acquisition and inevitably conducted a cross-sectional analysis by pooling available data. Efforts need to be made to obtain additional data from a variety of sources, though the authors have not been able to perform this task properly.

Another research topic is dividing CHP into high-capacity CHP and small-scale CHP and then analyzing them. High-capacity CHPs are installed to supply heat and power to specific areas, whereas small-scale CHPs are built to meet the demand for heat and power within specific buildings such as hospitals and schools or specific residential complexes. Since the main means of coping with the intermittency and uncertainty of RE is high-capacity CHP rather than small-scale CHP, future studies should consider limiting the scope of $\mathrm{CHP}$ to be investigated to high-capacity $\mathrm{CHP}$.

Author Contributions: All the authors made important contributions to this paper. H.-J.K. worked to collect data, and created more than half of the manuscript; J.-J.Y. carried out the literature review and wrote the remaining part of the manuscript and S.-H.Y. was responsible for designing and applying the economic and statistical models needed for obtaining the results.

Acknowledgments: This work was supported by the Korea Institute of Energy Technology Evaluation and Planning (KETEP) and the Ministry of Trade, Industry and Energy (MOTIE) of the Republic of Korea (No. 20184030202230).

Conflicts of Interest: The authors declare no conflict of interest.

\section{References}

1. Smyrgała, D. Fukushima and Energiewende: Impact on structure of power generation. Energy Sources Part B Econ. Plan. Policy 2017, 12, 332-337. [CrossRef]

2. Sun, C.; Zhu, X.; Meng, X. Post-Fukushima public acceptance on resuming the nuclear power program in China. Renew. Sustain. Energy Rev. 2016, 62, 685-694. [CrossRef]

3. Moss, T.; Becker, S.; Naumann, M. Whose energy transition is it, anyway? Organisation and ownership of the Energiewende in villages, cities and regions. Local Environ. 2015, 20, 1547-1563. [CrossRef]

4. Yazdanpanah, M.; Komendantova, N.; Ardestani, R.S. Governance of energy transition in Iran: Investigating public acceptance and willingness to use renewable energy sources through socio-psychological model. Renew. Sustain. Energy Rev. 2015, 45, 565-573. [CrossRef]

5. Chapman, A.J.; Itaoka, K. Energy transition to a future low-carbon energy society in Japan's liberalizing electricity market: Precedents, policies and factors of successful transition. Renew. Sustain. Energy Rev. 2018, 81, 2019-2027. [CrossRef]

6. Agrell, P.J.; Bogetoft, P. Economic and environmental efficiency of district heating plants. Energy Policy 2005, 33, 1351-1362. [CrossRef]

7. International Energy Agency. Combined Heat and Power: Evaluating the Benefits of Greatest Global Investment; International Energy Agency: Paris, France, 2008.

8. Afifi, S.N.; Hassan, M.G.; Zobaa, A.F. How market regulatory framework and policy affected the CHP development in meeting 2010 targets in the UK. Energy Sources Part B Econ. Plan. Policy 2012, 7, 331-338. [CrossRef]

9. Bianchi, M.; Branshini, L.; Pascale, A.D.; Peretto, A. Application of environmental performance of CHP systems with local and global approaches. Appl. Energy 2014, 130, 774-782. [CrossRef]

10. Cavallaro, F.; Zavadskas, E.K.; Raslanas, S. Evaluation of combined heat and power (CHP) systems using fuzzy shannon entropy and fuzzy TOPSIS. Sustainability 2016, 8, 556. [CrossRef]

11. Kim, G.E.; Lee, H.J.; Yoo, S.H. Willingness to pay for substituting coal with natural gas-based combined heat and power in South Korea: A view from air pollutants emissions mitigation. Sustainability 2018, 10, 1554. [CrossRef]

12. Kim, H.J.; Kim, J.H.; Yoo, S.H. Do people place more value on natural gas than coal for power generation to abate particulate matter emissions? Evidence from South Korea. Sustainability 2018, 10, 1740. [CrossRef] 
13. United States Environmental Protection Agency. Fuel and Carbon Dioxide Emissions Savings Calculation Methodology for Combined Heat and Power Systems. Available online: http:/ / www.epa.gov (accessed on 20 October 2018).

14. United States Department of Energy and United States Environmental Protection Agency. Combined Heat and Power: A Clean Energy Solution. 2012. Available online: http:/ / www.doe.gov (accessed on 15 November 2018).

15. Lucia, L.D.; Ericsson, K. Low-carbon district heating in Sweden-Examining a successful energy transition. Energy Res. Soc. Sci. 2014, 4, 10-20. [CrossRef]

16. Greene, W.H. Econometric Analysis, 7th ed.; Pearson: London, UK, 2012.

17. Ramsey, J.B. Tests for specification errors in classical linear least squares regression analysis. J. R. Stat. Soc. Ser. B 1969, 31, 350-371. [CrossRef]

18. Bassett, G.; Koenker, R. Asymptotic theory of least absolute error regression. J. Am. Stat. Assoc. 1978, 73, 618-622. [CrossRef]

19. Buchinsky, M. Estimating the asymptotic covariance matrix for quantile regression models: A Monte-Carlo study. J. Econom. 1995, 68, 303-338. [CrossRef]

20. World Bank. World Development Indicators. 2018. Available online: http://www.worldbank.org (accessed on 23 August 2018).

21. Euroheat and Power. District Heating and Cooling: Country by Country 2009 Survey; Euroheat and Power: Brussels, Belgium, 2011.

22. Euroheat and Power. District Heating and Cooling: Country by Country 2011 Survey; Euroheat and Power: Brussels, Belgium, 2013.

23. Euroheat and Power. District Heating and Cooling: Country by Country 2013 Survey; Euroheat and Power: Brussels, Belgium, 2015.

24. Euroheat and Power. District Heating and Cooling: Country by Country 2015 Survey; Euroheat and Power: Brussels, Belgium, 2017.

25. Mankiw, G.N.; Romer, D.; Weil, D.N. A contribution to the empirics of economic growth. Q. J. Econ. 1992, 107, 407-437. [CrossRef]

26. Li, K.; Kin, B. Impacts of urbanization and industrialization on energy consumption $/ \mathrm{CO}_{2}$ emissions: Does the level of development matter? Renew. Sustain. Energy Rev. 2015, 52, 1107-1122. [CrossRef]

27. Jarque, C.M.; Bera, A.K. A test for normality of observations and regression residuals. Int. Stat. Rev. 1987, 55, 163-172. [CrossRef]

28. Ju, H.-C.; Yoo, S.-H. The environmental cost of overhead power transmission lines: The case of Korea. J. Environ. Plan. Manag. 2014, 57, 812-828. [CrossRef]

29. Kim, H.-J.; Lim, S.-Y.; Yoo, S.-H. Is the Korean public willing to pay for a decentralized generation source? The case of natural gas-based combined heat and power. Energy Policy 2017, 102, 125-131. [CrossRef]

30. McKinsey and Company. Reducing U.S. Greenhouse Gas Emissions: How Much at What Cost? McKinsey and Company: New York, NY, USA, 2007.

31. Shipley, A.; Hampson, A.; Hedman, B.; Garland, P.; Bautista, P. Combined Heat and Power: Effective Energy Solutions for a Sustainable Future; ORNL/TM-2008/224; Oak Ridge National Laboratory: Oak Ridge, TN, USA, 2008.

32. Beith, R. Small and Micro Combined Heat and Power (CHP) Systems: Advanced Design, Performance, Materials and Applications; Elsevier: Amsterdam, The Netherlands, 2011.

33. Fogarty, T.; Lamb, R. Investing in the Renewable Power Market: How to Profit from Energy Transformation; John Wiley \& Sons: Hoboken, NJ, USA, 2012.

34. Shao, C.; Li, C.; You, X.; Wu, H.; Zhang, J.; Ding, Y.; Song, Y. Optimal coordination of CHP plants with renewable energy generation considering substitutability between electricity and heat. Energy Procedia 2016, 103, 100-105. [CrossRef]

(c) 2019 by the authors. Licensee MDPI, Basel, Switzerland. This article is an open access article distributed under the terms and conditions of the Creative Commons Attribution (CC BY) license (http://creativecommons.org/licenses/by/4.0/). 